\title{
Traumatismo cervical por arma de fuego en pediatría: apropósito de un caso
}

\section{Cervical trauma due to firearms in pediatrics: a case report}

\author{
Claudia Teme Lichi', Natalia Gómez', Kichiro Matsumura', Guido Cabral', José Jara'
}

\section{RESUMEN}

Introducción: Las lesiones cervicales por arma de fuego en pediatría tienen baja incidencia, aproximadamente a 5 a $10 \%$, con una mortalidad de 0 a $11 \%$. Objetivo: describir un caso de politraumatismo por arma de fuego, su manejo multidisciplinario y las consecuencias de la imprudencia a la exposición de niños a las mismas. Caso Clínico: paciente de sexo masculino, de 13 años de edad, con traumatismo de cara, cuello y tórax por herida accidental por arma de fuego (escopeta) con diagnósticos: Trauma Facial: fractura de maxilar superior e inferior; Trauma de cuello: lesión en cuerpo vertebral C4/C7 con perdigones incrustados; Trauma de tórax: contusión pulmonar derecha; Trauma de partes Blandas: con perdigones incrustados en celular subcutáneo. Ingresa al hospital de Trauma en choque hipovolémico presentando casi inmediatamente paro cardiorespiratorio, respondiendo a reanimación cardiopulmonar avanzada. TAC de cráneo al ingreso normal; al 8vo día se evidencia esquirla en sistema venoso de la base; TAC de cuello: se evidencia desplazamiento de tráquea y aire peri tráquea; AgioTAC: pseudoaneurisma en carótida interna izquierda. Fibrobroncospcopía: contusiones a nivel de tráquea; EDA: esófago y estómago con erosiones cubiertas por fibrina sin evidencia de fístula o perforación de víscera hueca. Tratamiento: en Asistencia Mecánica Respiratoria (ARM) por 10 días; inotrópicos por 72 hs, se realiza reparación de arteria carótida interna; colocación de arco de Erich por cirujanos maxilofaciales. Alta a sala de pediatría con buena evolución.

Palabras Claves: Arma de fuego, trauma, pediatría, lesiones vasculares.

\begin{abstract}
Pediatric cervical gun injuries have a low incidence, approximately 5 to $10 \%$, with a mortality of 0 to $11 \%$. Clinical Case: a 13-year-old male patient who presented with trauma to the face, neck and thorax due to accidental firearm injury (shotgun) with the following diagnoses: Facial trauma: fracture of the upper and lower jaw; Neck trauma: C4 / C7 vertebral body injury with embedded pellets; Chest trauma: right pulmonary contusion; Soft tissue trauma: embedded pellets in subcutaneous soft tissue. He was admitted to the Trauma hospital in hypovolemic shock, presenting almost immediate cardiorespiratory arrest, which responded to advanced cardiopulmonary resuscitation. CT scan of the skull was normal at admission; on the 8th day it showed evident splintering in the basal venous system; CT of the neck: tracheal displacement and evident peri-tracheal air; Angio CT: pseudoaneurysm in left internal carotid artery. Fibrobronchoscopy: bruises at the tracheal level; EDA: esophagus and stomach with fibrin-covered erosions without evidence of fistula or hollow viscera perforation. Treatment: on Mechanical Respiratory Assistance (MRA) for 10 days; inotropes for 72 hours, internal carotid artery repair was performed, Erich arch placement by maxillofacial surgeons. He was discharged to the pediatric ward with favorable evolution.
\end{abstract}

Keywords: Firearm, trauma, pediatrics, vascular lesions.

\footnotetext{
${ }^{1}$ Ministerio de Salud Pública y Bienestar Social, Hospital de Trauma “Prof. Dr. Manuel Giagni”. Asunción, Paraguay. Correspondencia: Claudia Teme Lichi Correo: clauteme1973@gmail.com Conflicto de interés: Los autores declaran no poseer conflicto de interés Recibido: 25/01/2019Aceptado: 19/02/2020 DOI: https://doi.org/10.31698/ped.47012020007
} 


\section{INTRODUCCIÓN}

Las lesiones traumáticas del cuello presentan particularidades especiales. Si bien la incidencia de lesiones cervicales por arma de fuego en pediatría es baja, la potencial gravedad de las mismas hace que su evaluación deba ser lo más exhaustiva posible y sin diferir la exploración. Tanto en el cuello como en el tórax se concentran estructuras vitales, como el aparato cardiovascular, linfático, respiratorio, digestivo, endócrino, nervioso y musculoesquelético ${ }^{(1)}$. Por tanto, las lesiones producidas en dichas zonas ameritan una evaluación adecuada y rápida porque pueden comprometer la vida del paciente. Estas intervenciones deben basarse en los hallazgos clínicos y radiológicos bien orientados por la anatomía ${ }^{(2,3)}$.

Saltea y col. propusieron la división del cuello anterior en tres zonas con el fin de unificar criterios de diagnósticos y manejo y realizar protocolos. La zona I está delimitada en la parte inferior por la línea superior del tórax que une las clavículas, y en la parte superior por una línea imaginaria que se traza a nivel del cartílago cricoides. La zona II abarca el área comprendida entre el cartílago cricoides y el hueso hioides en su proyección hasta el ángulo de la mandíbula. La zona III comprende el espacio existente entre el ángulo de la mandíbula y la base del cráneo. Las estructuras que albergan cada una de las zonas son blancos frecuentes de los proyectiles de armas de fuego ${ }^{(2,4)}$ y puede presentarse casos de migración del proyectil al penetrar en un vaso sanguíneo lentamente erosionando tejidos periféricos (diabrosis) ${ }^{(5,6)}$

Por otro lado de acuerdo a la gravedad, las heridas de cuello se clasifican en Grado 1 (menor): heridas penetrantes que no comprometen estructuras profundas. Grado 2 (moderadas): heridas penetrantes con compromiso de estructuras profundas (incluida lesión digestiva), sin lesión vascular o de vía aérea. Grado 3 (severa): heridas penetrantes con compromiso de estructuras profundas con lesión vascular o de vía aérea, con o sin repercusión sobre el SNC, únicas o combinadas. Grado 4 (crítica): heridas penetrantes que presentan hemorragia exanguinante y/o asfixia inminente.

Considerando la gravedad de las heridas por arma de fuego en los pacientes pediátricos y la necesidad de un manejo multidisciplinario se presenta el siguiente caso clínico de herida de grado 4.

\section{CASO CLÍNICO}

Paciente escolar, de 13 años de edad, sexo masculino, procedente de Pedro Juan Caballero, con traumatismo de cara, cuello y tórax por herida accidental por arma de fuego (escopeta); el incidente es referido por la madre quien no se encontraba presente en el lugar de los hechos, el paciente se hallaba en compañía de un familiar (primo) también menor de edad, manipulando el arma en cuestión con el posterior disparo accidental de la misma.

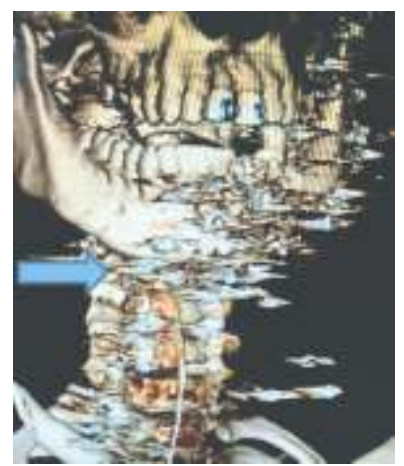

A

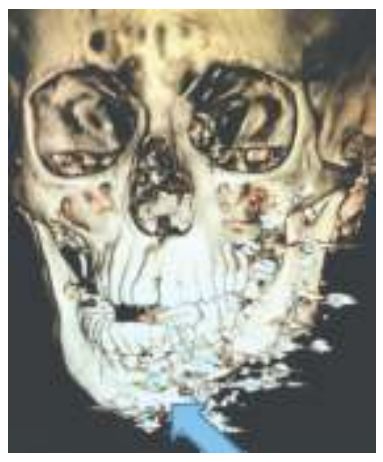

B

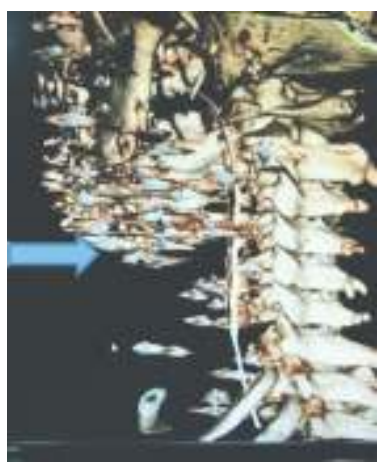

C

Figura 1. (A,B,C): TAC simple de Cara, Cráneo y cervical en diferentes proyecciones. Las flechas muestran: fractura de maxilar superior e inferior con múltiples esquirlas incrustadas (color celeste). 
Es trasladado por familiares a una clínica privada de la localidad donde ingresa lúcido, con Glasgow $15 / 15$, es evaluado por médicos de dicho centro decidiéndose ingreso a cirugía para toilette de las heridas de la cara y puntos de sutura. Posteriormente es remitido al Hospital de Trauma Manuel Giagni intubado y ventilado con bolsa autoinflable, llegando en choque hipovolémico, presentando a los 5 minutos de su ingreso a la urgencia del Hospital paro cardiorrespiratorio por lo que se procedió a maniobras de RCP avanzada con éxito.

La imagen tomográfica al ingreso evidencia fractura de maxilar superior e inferior; (Figura. 1. A,B, C) .

Posterior a estabilización del paciente se realizan estudios correspondientes: TAC de cráneo simple el cual se encuentra normal al ingreso, pero en el control realizado al 8vo día de internación se evidencia esquirla en sistema venoso de la base con aparente migración de la misma. (Figura 2 A y B) La TAC de cuello muestra desplazamiento de la tráquea y aire peri - traqueal y a nivel de las vertebras esquirlas. (Figura $3 \mathrm{~A}$ y B).

Trauma de Tórax: contusión pulmonar derecha sin evidencia de hemotórax ni neumotórax; Trauma de partes blandas: múltiples perdigones incrustados en celular subcutáneo; ingresa a la Unidad de Terapia Intensiva Pediátrica del Hospital de Trauma.

La Angio TAC evidencia Pseudoaneurisma en carótida interna izquierda (Figura 4 A); se realizó además una Fibrobroncoscopía que mostro múltiples contusiones en tráquea; la Endoscopía Digestiva Alta demostró la existencia de lesiones esofágicas: con erosiones lineales cubiertas por fibrina y hematina compatible con esofagitis por éxtasis; estómago: mucosa con lesiones redondeadas cubiertas por hematina sin evidencia de fístula o perforación.

El paciente ingreso a Asistencia Mecánica Respiratoria por 10 días lográndose extubación programada con éxito, soporte hemodinámico con inotrópicos por 72 hs. con lo cual se logró estabilidad; además requirió cirugías correspondientes: para reparación de arteria carótida interna (pseudoaneurisma) ( Figura 4 B) y de la vena yugular interna en la cual se halló una lesión en el acto quirúrgico y colocación de Arco de Erich por cirugía maxilofacial a fin de estabilizar fracturas de maxilares en plan de seguimiento por especialistas para posteriores eventuales cirugías.

El paciente fue dado de alta a sala de pediatría con buena evolución al cumplirse 1 mes de internación en UTIP.

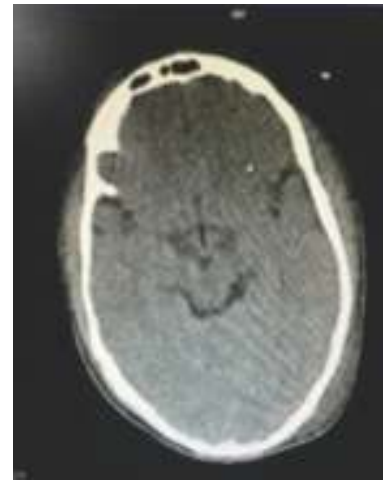

A

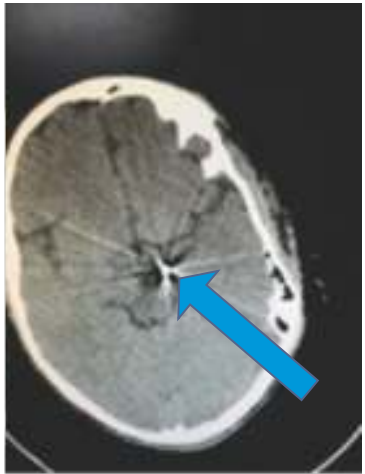

B
Figura 2. A) Primera TAC de cráneo, sin lesiones. B) Segunda Tac de cráneo se observan esquirlas (flecha).

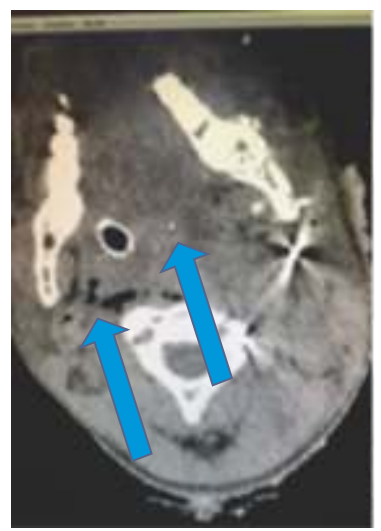

A

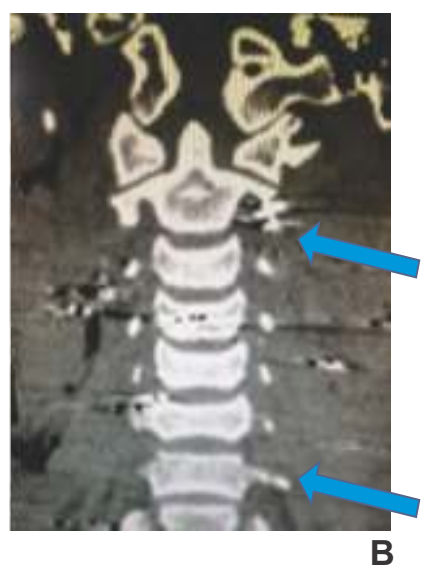

B
Figura 3. A) TAC de cuello se observa desplazamiento y aire peri traqueal. B) Esquirlas a nivel de las vertebras. 


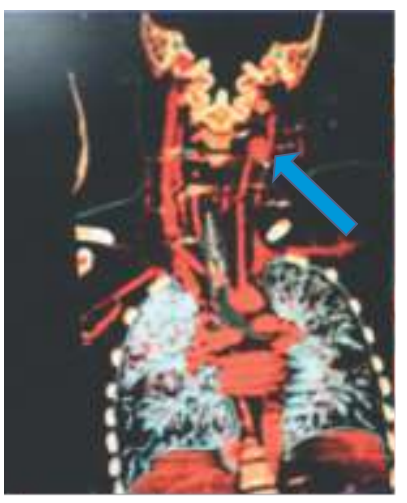

A

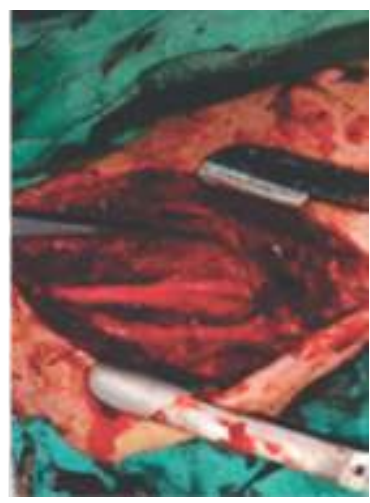

B

Figura 4. A) AngioTAC con Pseudoaneurisma de la carótida (flecha). B) Acto quirúrgico de reparación de la lesión vascular.

\section{DISCUSIÓN}

En el caso clínico descrito, se demuestra la importancia del manejo multidisciplinario, considerando las múltiples estructuras pasibles de lesión según la zona del cuello afectada, muchas de las cuales son de importancia vital ${ }^{(7,8)}$. La complejidad del caso requirió un manejo multidisciplinario (intensivistas, cirujanos vasculares, cirujanos infantiles, cirujanos maxilofaciales, endoscopistas, infectólogos).

Los buenos resultados terapéuticos dependen de un alto grado de sospecha de las lesiones por lo que consideramos de suma importancia la presentación de este caso, demostrando que la rápida toma de decisiones, solicitud de estudios dirigidos hacia lesiones según zonas anatómicas y manejo

\section{REFERENCIAS BIBLIOGRÁFICAS}

1. Fiorentino J, Gómez Traverso R. Heridas por arma de fuego en pediatría. Rev. de Cir. Infantil. 2001; 10(4): 211-215.

2. Quintero L, Hurtado A. Abordaje inicial en los servicios de urgencias. In: Trauma de cuello. 2005. p. 149-166.

3. Pereira Graterol C, Bravo Romero A. "Proyectil deglutido": Ilustración de una trayectoria raramente observada en trauma cervical pediátrico por arma de fuego. Cir. Pediatr. 2007; 20(4):229-231.

multidisciplinario, mejoran el pronóstico de vida en estos traumas con riego elevado para la vida ${ }^{(4)}$.

En la población pediátrica las diferencias anatómicas con la población adulta son muchas, las cuales favorecen y complican el pronóstico de los primeros. El cuello de los niños es relativamente más corto, lo cual favorece que sea menor la incidencia en él de lesiones anteriores por trauma directo. Sin embargo; el mayor diámetro cefálico que existe en los pacientes pediátricos hace que el cuello esté más expuesto a lesiones por aceleración y desaceleración. La vía aérea de los niños tiene a su vez una disposición más cefálica y anterior y su punto más estrecho es en el cartílago cricoides a nivel de C4, mientras que en los adultos este punto se encuentra a nivel de C7. Otro hecho es que el cuello de los niños es más flexible, por lo que las lesiones no son tan evidentes por radiografía, sin embargo la AngioTAC puede considerarse como un método razonable de evaluación y que podría ayudar pata determinar conductas y decisiones quirúrgicas principalmente el lesiones vasculares como el caso presentado ${ }^{(4)}$.

Finalmente, es importante crear conciencia y consejo oportuno por parte de los pediatras a los padres sobre el peligro que existe al permitir la existencia de armas de fuego al alcance de los niños a fin de prevenir este tipo de accidentes con regulación efectiva de la venta de armas y municiones, además de licencia para utilizarlas $^{(9,10,11)}$ ya que en la actualidad la influencia negativa especialmente de los medios de comunicación donde se observa hasta un $80 \%$ de programación con escenas de violencia y promoción del uso de armas ha aumentado considerablemente ${ }^{(12)}$.

4. Millán M, Gómez J, Hernández J. Manejo del trauma penetrante cervical de Zona II. Trabajo de Investigación. Cuad. Cir. 2008; 22:11-17.

5. García-Valadez L, Hernández-Telléz I, Ibañez-Guerrero O. Epidemiología de las heridas por proyectil de arma de fuego en el Hospital Central Militar de México. Rev. Milit Mex. 2015; 69(3):204-217. 
6. FiorentinoJ, Turina D. Manejo selectivo de una Herida transfixiante cervicotorácica por arma de fuego. Rev Hosp Niños. 2011; 53(240):24-31.

7. Norton J, Whittaker G. Shooting up?. Analysis of 182 gunshot unjuries presenting to a London major trauma centre over a sever-year period. Ann R Coll Surg Engl. 2018; 100(6):464-474.

8. Hernández-Velázquez E, Loyola-García U, Betancourt M. Control de daños en trauma penetrante de cuello: Abordaje Multidisciplinario. Cirujano General. 2002; 34(2):138-42.

9. Wijaya A, Ayusta M, Niryana W. Air guns Wound: bihemispheric penetrating brain injury in a pediatric patient. BJR Case Rep. 2019;5(2):20180070.
10. Khan U, Kamal N. Pediatric air gun shot injury. Saudi Med J. 2014;35(12):1507-1509.

11. Acosta J, Servín R. Heridas por armas de fuego en pacientes pediátricos. Rev. de la Facultad de Medicina de la Universidad Nacional del Nordeste Argentina. 2014; 34(1):34-39.

12. Sotelo-Cruz N, Cordero-Olivares A, Woller-Váquez R. Heridas por proyectil de arma de fuego en niños y adolescentes. Cir Ciruj. 2008; 68(5):204-210. 